\title{
Liquid Fuel Production by Zeolite-A Catalyzed Pyrolysis of Mixed Cassava Solid Waste and Rubber Seed Oil
}

\author{
WASINTON SIMANJUNTAK ${ }^{1 *}$, KAMISAH DELILAWATI PANDIANGAN", \\ ZIPORA SEMBIRING ${ }^{1}$ and AGUSTINA SIMANJUNTAK ${ }^{1}$
}

1Department of Chemistry, University of Lampung, Bandar Lampung, Indonesia.

${ }^{\star}$ Corresponding author E-mail: wasinton.simanjuntak@fmipa.unila.ac.id

http://dx.doi.org/10.13005/ojc/350108

(Received: September 13, 2018; Accepted: January 20, 2019)

\begin{abstract}
In this investigation, a mixture of cassava (Manihot esculenta) solid waste and rubber seed oil was subjected to pyrolysis for liquid fuel production. A series of pyrolysis experiments was conducted with fixed composition of $50 \mathrm{~g}$ cassava solid waste and $150 \mathrm{~mL}$ rubber seed oil. The experiments were conducted using zeolite-A synthesized from rice husk silica and aluminum metal through sol-gel route and subsequently calcined at different temperatures as catalyst. The main purpose of this study was to investigate the effect of calcination temperatures of the catalyst on the chemical composition of the liquid fuel obtained. The pyrolysis experiment was commenced at room temperature and allowed to reach peak temperature of $350^{\circ} \mathrm{C}$, and the composition of liquid fuel produced was analyzed using gas chromatography-mass spectrometry (GC-MS) technique. The results of GC-MS analyses reveal that liquid fuels composed of a series of organic compounds, broadly belong to hydrocarbon, alcohol, ester, ketone, aldehyde, and acid. The results also display significant effect of the calcination temperatures of the catalyst on the composition of the liquid for hydrocarbon contents in particular, the fuel with the highest hydrocarbon content of $90 \%$ was obtained using the catalyst calcined at $800^{\circ} \mathrm{C}$, suggesting that the use of the particular catalyst is the optimum condition. Based on the hydrocarbon content of the liquid fuels, it is concluded that the zeolites exhibited considerably high ability to enhance the formation of hydrocarbon and simultaneously suppress the formation of oxygenated compounds.
\end{abstract}

Keywords: Liquid fuel, Pyrolysis, Cassava Manihot esculenta solid waste, Zeolite-A, Rubber seed oil.

\section{INTRODUCTION}

In the context of current energy situation, in which world reliance on fossil fuels is no longer realistic, biomass derived fuels (biofuels) are the most promising solution. At present, utilization of biomass for production of alternative energy sources continues to receive great interest since biomass can be converted into different types of biofuel using biological, chemical and physical processes. Among the biomass to liquid fuel conversion processes, pyrolysis continuous to attract growing interest ${ }^{1-3}$, because this method offers several advantages, such as simplicity of the process, the applicability

This is an Open Access article licensed under a Creative Commons license: Attribution 4.0 International (CC- BY). Published by Oriental Scientific Publishing Company @ 2018

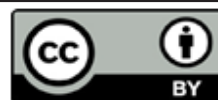


of the resulted fuels for various applications, such as for boilers and turbines ${ }^{4}$, and the possibility to improve the quality of the fuel by converting it into fuel which suites the application with more stringent requirements, such as bio-gasoline $e^{5,6}$. In recognizing these advantages, extensive efforts have been devoted to develop production of liquid fuel by pyrolysis of different biomass raw materials, either single or mixture of two raw materials. This method has been applied to produce liquid fuel from different types of single substrate, such as wild reed ${ }^{7}$, rice husk ${ }^{4}$, Napier grass ${ }^{8}$, crude palm oil ${ }^{9}$, palm oil ${ }^{1}$, sugarcane bagasse and sludge palm oil ${ }^{2,3}$.

Production of liquid fuel from biomass mixed with other raw materials has also been reported in many studies, taking advantage of suggested synergetic effect of mixed raw materials ${ }^{10}$. Several previous studies on co-pyrolysis of mixed raw materials are co-pyrolysis of forest wastes with waste tires ${ }^{10}$, wastes coconut shells ${ }^{11}$, rice husk and waste tire ${ }^{12}$, cotton straw and polypropylene ${ }^{13}$, and mixture of corn cobs with polypropylene ${ }^{14}$.

In application of pyrolysis technique, catalyst is acknowledged as one the main factors not only to lower the pyrolysis temperature, but also determine the types of product resulted ${ }^{15}$. Taking this advantageous feature of pyrolysis process, various catalyst systems have been studied, and of special interest are zeolites. This particular type of materials is known as acidic catalyst and has been reported to promote deoxygenation of biomass during the pyrolysis, therefore reduces the quantity of oxygen-containing products, resulted in increased formation of hydrocarbons ${ }^{16,17}$. It is suggested that zeolites function to release oxygen from biomass during the pyrolysis through three mechanisms, i.e decarbonylation to release of oxygen as carbon monoxide, decarboxylation to release oxygen as carbon dioxide, and Hydrodeoxygenation to release oxygen as water ${ }^{5,18}$.

In this study, co-pyrolysis of sugarcane bagasse and rubber seed oil was carried out. These two raw materials were selected considering their availability and their existence as agricultural residues with very limited use. A series of pyrolysis experiments was conducted using zeolite-A synthesized from rice husk silica and aluminum metal using sol-gel method as catalyst. Four samples were derived from the zeolite precursor and subjected to different calcination temperatures of $600,700,800$, and $900^{\circ} \mathrm{C}$ for 6 hours. The calcined zeolites were then tested as catalyst in the pyrolysis experiments, with the main purpose to study the effect of calcination temperatures of the catalysts on chemical composition of liquid fuels obtained. The liquid fuels produced were characterized using GC-MS method to compare the composition of liquid fuels produced using different catalysts.

\section{MATERIALS AND METHODS}

The chemicals used in this study, sodium hydroxide, nitric acid, are reagent grade obtained from Sigma Aldrich. The aluminum metal rods ware purchased from CV Aluminium Jaya Perkasa, Jakarta. Rice husk was obtained from local rice milling industry in Bandar Lampung. A Nabertherm electrical furnace (Lilienthal, Germany) was used for calcination treatment. A laboratory scale pyrolysis unit was used for pyrolysis experiments and the GCMS-QP2010 SE SHIMADZU, equipped with MS Library system NIST12.LIB and WILEY229. LIB Wiley 275 , was used for analysis and identification of the chemical composition of the liquid fuels produced.

Rice husk was obtained from local paddy farmer in Bandar Lampung. Rubber seeds were collected from rubber plantation in Natar South Lampung, and cassava solid waste was obtained from cassava flour company in Bandar Lampung.

Rice husk silica was obtained using an alkali extraction method reported in previous study ${ }^{19}$. Briefly, the extraction process involves boiling of $50 \mathrm{~g}$ dried husk mixed with $500 \mathrm{~mL}$ of $1.5 \% \mathrm{NaOH}$ solution for $30 \mathrm{~min}$, leaving the mixture at room temperature for 24 hours. After the completion of extraction, the mixture was filtered through a millipore filter and the filtrate which contains silica (silica sol) was acidified by dropwise addition of $10 \% \mathrm{HNO}_{3}$ solution until the sol was completely converted into gel. The gel was aged for three days, rinsed repeatedly with deionized water to remove the excess of acid, and then oven dried at $110^{\circ} \mathrm{C}$ for eight hours and ground into powder. 
Zeolite-A was prepared according to the general formula of $\left(\mathrm{Na}_{2} \mathrm{O} \cdot \mathrm{Al}_{2} \mathrm{O}_{3} \cdot 2 \mathrm{SiO}_{2} \cdot 4 \cdot 5 \mathrm{H}_{2} \mathrm{O}\right)$. Typical preparation was conducted by dissolving $40 \mathrm{~g} \mathrm{NaOH}$ in $350 \mathrm{~mL}$ of distilled water, and the solution was divided into two parts. The first part with the volume of $100 \mathrm{~mL}$ was used as a solvent to dissolve $27 \mathrm{~g}$ of Al metal, and the second part, with the volume of 250 $\mathrm{mL}$, to dissolve $60 \mathrm{~g}$ of rice husk silica. The silica and aluminum solutions were then thoroughly mixed using a laboratory blender, and then the mixture was transferred into a teflon chamber and allowed for $24 \mathrm{~h}$ at room temperature, during which the mixture transformed into gel. To obtain dry solid, the gel was oven dried at $110^{\circ} \mathrm{C}$ for $24 \mathrm{~h}$ and then ground into powder. Four powder samples were prepared and subjected to different calcination temperatures of $600,700,800$, and $900^{\circ} \mathrm{C}$ for six hours.

Pyrolysis experiment was performed in a laboratory scale pyrolysis unit. Prior to pyrolysis experiment, the sample was prepared by mixing 50 $\mathrm{g}$ of cassava solid waste and $150 \mathrm{~mL}$ of rubber seed oil. The raw materials were mixed and allowed for $24 \mathrm{~h}$ to allow the two raw materials to mix thoroughly. To commence the experiment, $10 \mathrm{~g}$ of catalyst was added into the mixture, and the sample was transfer into pyrolysis unit. The peak temperature for pyrolysis was set at $350^{\circ} \mathrm{C}$, and pyrolysis was run by heating the reactor until the peak temperature was reached at which the pyrolysis process was allowed to proceed for 60 minutes. The liquid fuel obtained was transferred into separatory funnel and allowed to separate between water phase and organic phase (liquid fuel). The liquid fuels were then then anaylzed by GC-MS.

\section{RESULTS AND DISCUSSION}

Prior to pyrolysis experiments with mixed raw materials, the experiments with single raw material (cassava solid waste and rubber seed oil) were conducted using the catalyst calcined at $600^{\circ} \mathrm{C}$ as a representative. The GC-chromatograms are presented in Figure 1.

As can be seen in Fig. 1, the chromatograms obtained from the experiments with single raw material are characterized by relatively few peaks and low intensities. In the case of cassava solid waste it was also observe that the quantity of liquid product is very small, and most of the product was solid residue, suggesting that pyrolysis of this solid raw material is not promising for liquid fuel production. In the case of rubber seed oil, the main limitation is significantly low intensities of the peaks, which most likely due to production of gaseous product as observed during the experiments. With such limitations, the use of cassava solid waste and rubber seed oil as single material was not considered further.
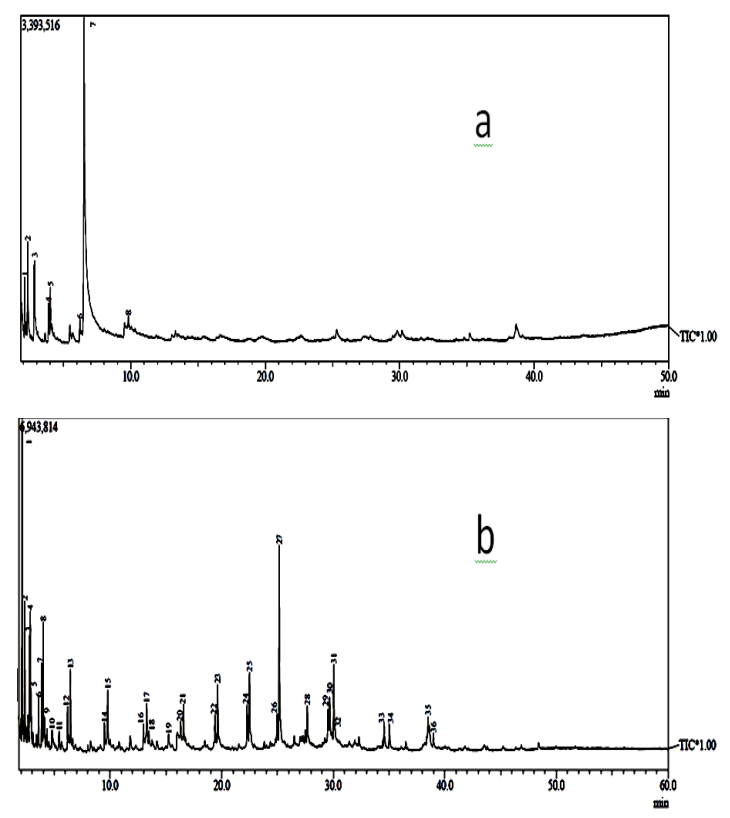

Fig. 1. GC-chromatogram of liquid fuel obtained by pyrolysis of cassava solid waste (a) and rubber seed oil (b) using uncalcined catalyst

The first pyrolysis experiment using mixed raw materials was carried out using uncalcined catalyst, and the GC chromatogram of the liquid fuel obtained is shown in Figure 2.

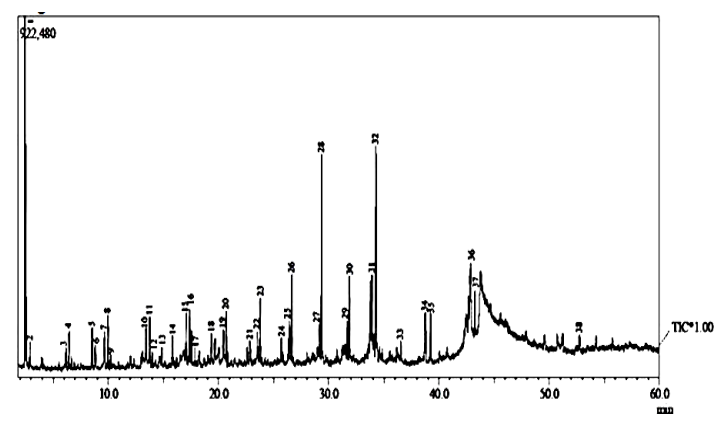

Fig. 2. GC-chromatogram of liquid fuel obtained by pyrolysis of mixed cassava solid waste and rubber seed oil using uncalcined catalyst

As typical of pyrolysis products of biomass sample reported in literatures ${ }^{3,19,20}$, the GC chromatogram of the liquid fuel presented in 
Fig. 2 indicates that the liquid fuel is composed of large number of compounds, and it should be acknowledged that not all of them were identified. With the aid of the MS Library system NIST12.LIB and WILEY229.LIB Wiley 275 , as many as 38 compounds were tentatively identified, and they are listed in Table 1.

Table 1: The chemical composition of the liquid fuel obtained by pyrolysis of mixed cassava solid waste and rubber seed oil using uncalcined catalyst

\begin{tabular}{|c|c|c|c|c|}
\hline $\begin{array}{c}\text { Peak } \\
\text { no }\end{array}$ & $\begin{array}{l}\text { Ret. time } \\
\text { (Minute) }\end{array}$ & Percentage(\%) & $\begin{array}{c}\text { Compound } \\
\text { name }\end{array}$ & Formula \\
\hline 1 & 2.435 & 8.07 & Ethanol & $\mathrm{C}_{2} \mathrm{H}_{6} \mathrm{O}$ \\
\hline 2 & 2.905 & 0.99 & Acetic acid & \\
\hline 3 & 6.173 & 0.64 & Ethylbenzene & \\
\hline 4 & 6.439 & 1.40 & 1,2-Dimethylbenzene & \\
\hline 5 & 8.533 & 1.70 & 2-Octene & \\
\hline 6 & 8.829 & 1.24 & Cyclooctane & \\
\hline 7 & 9.652 & 2.40 & Octane & \\
\hline 8 & 9.975 & 2.27 & 2-Nonene & \\
\hline 9 & 10.194 & 0.98 & Nonane & \\
\hline 10 & 13.441 & 1.66 & Buthylbenzene & \\
\hline 11 & 13.772 & 1.97 & Limonene & \\
\hline 12 & 13.977 & 0.71 & 1-Decene & \\
\hline 13 & 14.848 & 0.84 & 3-Decene & $\mathrm{C}_{1}$ \\
\hline 14 & 15.828 & 1.74 & Cyclodecane & \\
\hline 15 & 17.072 & 2.17 & 3,5-Dimethyloctane & \\
\hline 16 & 17.369 & 2.17 & 1-Undecene & \\
\hline 17 & 17.847 & 0.79 & 2-Undecene & $\mathrm{C}_{11}$ \\
\hline 18 & 19.333 & 1.79 & 3-Undecene & \\
\hline 19 & 20.427 & 1.98 & 4-Undecene & \\
\hline 20 & 20.693 & 2.78 & Penthylbenzene & \\
\hline 21 & 22.834 & 1.78 & Isobuthyltoluene & \\
\hline 22 & 23.522 & 1.37 & Undecane & \\
\hline 23 & 23.771 & 2.92 & 1-Dodecene & \\
\hline 24 & 25.681 & 1.40 & Dodecane & $\mathrm{C}$ \\
\hline 25 & 26.412 & 2.11 & Hexylbenzene & $\mathrm{C}_{1}$ \\
\hline 26 & 26.639 & 4.42 & 1-Tridecene & \\
\hline 27 & 29.121 & 1.45 & Tridecane & \\
\hline 28 & 29.339 & 9.33 & 2-Phenyl Heptane & $\mathrm{C}_{1}$ \\
\hline 29 & 31.679 & $1.98 \quad 1-1$ & I-Methylhexylbenzene & $\mathrm{C}_{13}$ \\
\hline 30 & 31.864 & 3.83 & 1-Tetradecene & \\
\hline 31 & 33.904 & 5.95 & Pentadecane & $\mathrm{C}_{15}$ \\
\hline 32 & 34.279 & 10.75 & 1-Hexadecene & $\mathrm{C}_{16} \mathrm{H}_{32}$ \\
\hline 33 & 36.536 & 0.92 & Hexadecane & $\mathrm{C}_{16} \mathrm{H}_{34}$ \\
\hline 34 & 38.760 & 3.38 & 8-Pentadecanone & $\mathrm{C}_{15} \mathrm{H}_{30} \mathrm{O}$ \\
\hline 35 & 39.242 & 2.47 & 2-Heptadecanone & $\mathrm{C}_{17} \mathrm{H}_{34} \mathrm{O}$ \\
\hline 36 & 42.881 & 4.39 & Linoleic acid & $\mathrm{C}_{18} \mathrm{H}_{32} \mathrm{O}_{2}$ \\
\hline 37 & 43.266 & 2.39 & Methyl Linolelaidate & $\mathrm{C}_{19} \mathrm{H}_{34} \mathrm{O}_{2}$ \\
\hline 38 & 52.765 & 0.86 & Methyl Stearate & $\mathrm{C}_{19} \mathrm{H}_{38} \mathrm{O}_{2}$ \\
\hline
\end{tabular}

The complexity of chemical composition of liquid fuels derived from pyrolysis of biomass makes it is practically very difficult to describe the characteristic of liquid fuel based on single component. In order to simplify the results for easier interpretation of the compositional data liquid fuel, in previous studies, the identified components liquid fuel were commonly assigned to more general categories of organic compounds. As an example, the components of liquid fuel obtained by pyrolysis of wild reed ${ }^{7}$ were grouped into seven categories i.e acids, oxygenates, phenolics, aliphatic hydrocarbons, monocyclic aromatics, polycyclic aromatics, and nitrogen-containing species. In the study it was also found that the oxygen-containing compounds are the dominant components of the liquid, which is quite different with the existence of hydrocarbon as the main constituent of the liquid fuel observed in this study. In another study ${ }^{8}$ the components of liquid fuel obtained by pyrolysis were divided into groups of hydrocarbon, aromatics, phenolics, alcohol, and others.

Adopting the method reported in literatures, the 38 compounds identified in the sample produced from the experiment without the use of catalyst (Fig. 2) were classified into five more common categories of chemical compounds, as indicated in Table 1. The five categories are hydrocarbon, ketone, ester, acid, and acid. In addition to simpler presentation of the data, categorization of the chemical components of liquid fuel is useful for estimation of the relative composition of the fuel. Fig. 3 is the relative composition of the liquid fuel based on the GC chromatogram shown in Fig. 2. As can be seen in Fig. 3, the main component of the liquid fuel is hydrocarbon which contributes $78 \%$ to the composition. The existence of hydrocarbons as the prime component is advantageous from the practical point of view since hydrocarbon is considered as the most ideal fuel. Apart from this advantageous compositional characteristic, the presence of less desirable components, reflecting the need for upgrading process of fuel for practical utilization.

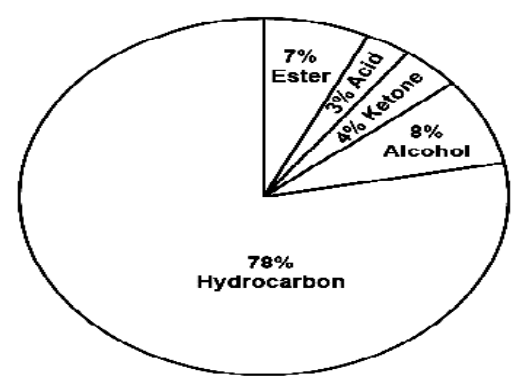

Fig. 3: Relative composition of liquid fuel obtained by pyrolysis of mixed cassava solid waste and rubber seed oil using uncalcined catalyst

To gain insight on the effect of catalyst as well as the effect of calcination temperatures of the catalyst on the chemical composition of the liquid fuel produced, the pyrolysis experiments using the catalysts calcined at different temperatures of $600,700,800$, and $900^{\circ} \mathrm{C}$ were carried out at the same experimental condition to that applied in the experiment without catalyst. The liquid fuels obtained 
from the experiments were then analyzed similarly and the relative composition of each of the fuels was calculated for comparison. The GC-chromatograms together with pie charts showing relative composition of liquid fuels are presented in Fig. 4. In general, it can be seen that the chromatograms are quite similar, suggesting the presence of the same compounds in the fuels, although some differences should also be appreciated.
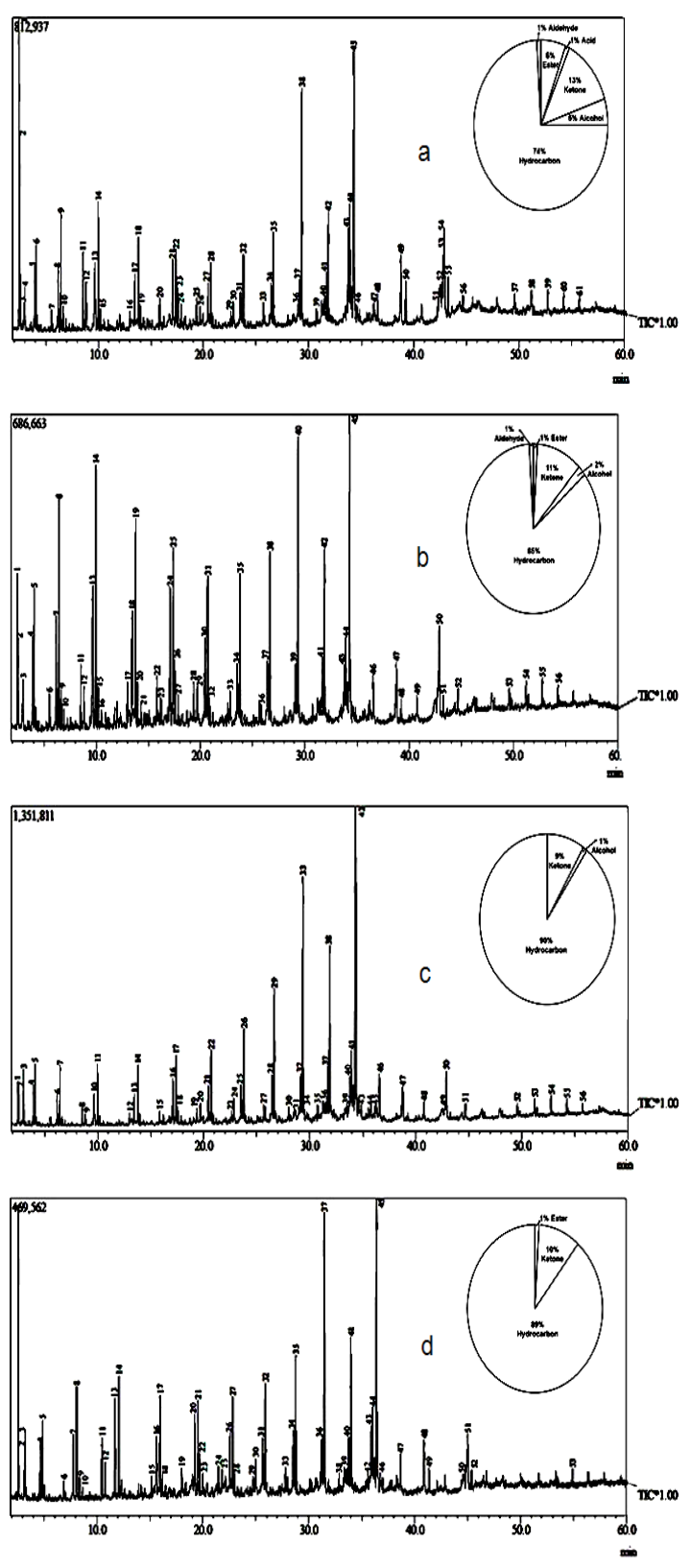

Fig. 4. GC-chromatograms and relative compositions of liquid fuel obtained using catalyst calcined at $600^{\circ} \mathrm{C}(\mathrm{a})$, $700^{\circ} \mathrm{C}$ (b), $800^{\circ} \mathrm{C}$ (c), and $900^{\circ} \mathrm{C}$ (d)
To summarize, the composition of liquid fuels produced from the all experiments are compiled in Table 2.

Table 2: Relative composition of liquid fuels produced using different catalysts

\begin{tabular}{|c|c|c|c|c|c|c|}
\hline \multirow[t]{2}{*}{ Catalyst } & \multicolumn{6}{|c|}{ Liquid fuel composition (\% relative) } \\
\hline & Hydroca & Acid & Ester & etone & Alcohol & Aldehyde \\
\hline Uncalcined & 78 & 3 & 7 & 4 & 8 & - \\
\hline $\begin{array}{l}\text { Calcined at } \\
600^{\circ} \mathrm{C}\end{array}$ & 74 & 1 & 6 & 13 & 5 & 1 \\
\hline $\begin{array}{l}\text { Calcined at } \\
700^{\circ} \mathrm{C}\end{array}$ & 85 & - & 11 & 1 & 2 & 1 \\
\hline $\begin{array}{l}\text { Calcined at } \\
800^{\circ} \mathrm{C}\end{array}$ & 90 & - & - & 9 & 1 & - \\
\hline $\begin{array}{l}\text { Calcined at } \\
900^{\circ} \mathrm{C}\end{array}$ & 89 & - & 1 & 9 & - & - \\
\hline
\end{tabular}

As can be seen in Table 2, in all liquid fuels obtained from different experiments hydrocarbon emerges as the prominent constituent. Related to the calcination temperatures of the catalyst, the main pattern observed is a trend of increased hydrocarbon contents up to calcination temperature of $800^{\circ} \mathrm{C}$, at which the hydrocarbon content reached the highest percentage of $90 \%$, and then slightly decreases to $89 \%$ with the use of catalyst calcined at $900^{\circ} \mathrm{C}$. This finding demonstrate the ability of zeolites used to suppress the formation of oxygenated compounds, as has been reported by others ${ }^{6,17}$. In addition to the catalysts performance, the potential of the raw materials investigated for production of hydrocarbon rich liquid fuel should also be acknowledged.

Another component that suggests the influence of calcination temperatures of the catalyst on the composition of the liquid fuels is alcohol. For this particular component, the experimental results display continuous decrease of the relative percentage from $8 \%$ to practically undetected level in the liquid fuel produce using the catalyst calcined at $900^{\circ} \mathrm{C}$. For the rest of the components, no general trend could be specified and therefore, their formation during the pyrolysis process as an effect of calcination temperatures of the catalyst could not be generalized.

Another important result showing the role of catalyst is the tendency of simpler composition of the fuels with increased calcination temperatures of the catalyst. As can be seen, the liquid fuel produced with catalyst calcined at $600^{\circ} \mathrm{C}$ is composed of six 
categories of compounds, and decreased into five groups in the liquid fuel obtained using the catalyst calcined at $700^{\circ} \mathrm{C}$, and decreased further into only three groups in the liquid fuels produced using the catalysts calcined at 800 and $900^{\circ} \mathrm{C}$. The potential of the catalysts and raw materials used is also reflected by a very small or undetected acid in the fuels, since acid is considered as the most unwanted component of liquid fuel taking hydrocarbon content as the most important component of liquid fuel into consideration, it is then concluded that the catalyst subjected to calcination temperature of $800^{\circ} \mathrm{C}$ as the catalyst with the highest performance.

\section{CONCLUSION}

The results of this study demonstrated the potential of production of liquid fuel with high hydrocarbon content by pyrolysis of mixed cassava solid waste and rubber seed oil. The results also display the very significant performance of zeolite-A synthesized to enhance the production of hydrocarbons and simultaneously reduce the formation of oxygenated compounds, primarily the acids which are considered as the most unwanted constituent of fuel. Taking hydrocarbon content as the most important component of liquid fuel into consideration, it is then concluded that the catalyst subjected to calcination temperature of $800^{\circ} \mathrm{C}$ as the catalyst with the highest performance.

\section{ACKNOWLEDGMENT}

The authors gratefully acknowledge The Directorate of Research and Community Service, The Ministry of Research, Technology, and Higher Education, Republic of Indonesia, for financial support through research grant, Hibah Penelitian Berbasis Kompetensi 2018, Contract Number: 384/UN26.21/PN/2018. The authors also acknowledge Integrated Laboratory and Centre for Technology Innovation (LTSIT), Lampung University for technical assistance.

\section{CONFLICT OF INTEREST}

This study was undertaken with fully financial support from Educational Institution under The Ministry of Research, Technology, and Higher Education, Republic of Indonesia, and no conflict of interest exists associated with this study.

\section{REFERENCES}

1. Sangdara, P.; Subsadsana, M.; Ruangviriyachai, R. Orient. J. Chem., 2017, 33(5), 2257-2262.

2. Supriyanto, R.; Simanjuntak, W.; Pandiangan, K. D.; Situmeang, R. T. M.; Ahmadhani, M. Y. Orient. J. Chem., 2018, 34(2), 1533-1540.

3. Simanjuntak, W.; Sembiring, S., Pandiangan, K. D.; Pratiwi, E.; Syani, F. Orient. J. Chem., 2017, 33(6), 3218-3224.

4. Zheng, J. L.; Kong, Y. P.; Energy Convers. Manage., 2010, 51, 182 - 188.

5. Mortensen, P. M.; Grunwaldt, J. D.; Jensen, P. A.; Knudsen, K. G.; Jensen, A. D. Appl. Catal., A., 2011, 407, 1 - 19.

6. Wang, T.; Zhang, Q.; Ding, M.; Wang, C.; Li, Y.; Zhang, Q.; Ma, L. Energy Procedia., 2017, 105, 858-863.

7. Yoo, M. Y.; Park, Y. H.; Park, Y. K.; Park, S. H., Energies., 2016, 9(201), 1-9.

8. Mohammed, I.Y.; Kazi, F. K.; Yusup, S.; Alaba, P. A.; Sani, Y. M.; Abakr, Y. A. Energies., 2016, 9(246), 1 - 17.

9. Subsadsana, M.; Ruangviriyachai, C. Orient. J. Chem., 2016, 32(2), 839 - 844

10. Martínez, J. D., Veses, A.; Mastral, A. M.; Murillo, R.; Navarro, M. V.; Puy, N.; Artigues, A.; Bartrolí, J.; García, T. Fuel Process.
Technol., 2014, 119, 263 - 270.

11. Pirajan, J. C. M.; Giraldo, L.; Orient. J. Chem., 2013, 29(3), 877 - 887.

12. Hossaina, M. S., Islama, M. R.; Rahmana, M. S.; Kadera, M. A.; Haniub, H. Energy Procedia., 2017, 110, 453 - 458.

13. Hua, D.; Wu, Y.; Chen, Y.; Li, C.; Yang, M.; Lu, X. Catalysts., 2015, 5, 2085 - 2097.

14. Supramono, D.; Haqqyana, J.; Nasikin, S. M. Int. J. Tech., 2016, 8, 1382-1392.

15. Demiral, I.; Sensoz, S. Bioresour. Technol., 2008, 99, 8002 - 8007.

16. Park, H. J.; Heo, H. S.; Jeon, J. K.; Kim, J.; Ryoo, R.; Jeong, K. E.; Park, Y. K. Appl. Catal., B 2010, 95, 365 - 373.

17. Kim, J. W.; Park, S. H.; Jung, J.; Jeon, J. K.; Ko, C. H.; Jeong, K. E.; Park, Y. K. Bioresour. Technol., 2013, 136, 431 - 436.

18. Dutta, A., Schaidle, J. A., Humbird, D., Baddour, F. G., Topics in Catalysis., 2016, 59(1), 2 - 18.

19. Simanjuntak, W.; Pandiangan, K. D.; Sembiring, S.; Syani, F.; Situmeang, R. T. M. Orient. J. Chem., 2016, 32(4), 2079 - 2085.

20. Mullen, C. A.; Boateng, A. A. Energy. Fuels., 2008, 22, $2104-2109$. 